\title{
BMJ Open High birth weight in a suburban hospital in Cameroon: an analysis of the clinical cut-off, prevalence, predictors and adverse outcomes
}

\author{
Simeon-Pierre Choukem, ${ }^{1,2,3}$ Tsi Njim, ${ }^{1}$ Julius Atashili, ${ }^{4}$ Julian P Hamilton-Shield, ${ }^{5}$ \\ Robinson $\mathrm{Mbu}^{6}$
}

To cite: Choukem S-P Njim T, Atashili J, et al. High birth weight in a suburban hospital in Cameroon: an analysis of the clinical cutoff, prevalence, predictors and adverse outcomes. BMJ Open 2016;6:e011517. doi:10.1136/bmjopen-2016011517

- Prepublication history for this paper is available online. To view these files please visit the journal online (http://dx.doi.org/10.1136/ bmjopen-2016-011517)

Received 14 February 2016 Revised 26 May 2016 Accepted 6 June 2016

CrossMark

For numbered affiliations see end of article.

\section{Correspondence to} Professor Simeon-Pierre Choukem;

schoukem@gmail.com

\section{ABSTRACT}

Background and aims: High birth weight (HBW) increases the risk of maternal and fetal morbidity and mortality. Its prevalence and adverse outcomes may be reduced if risk factors are identified and managed during pregnancy. The cut-off value for HBW remains debatable. The objectives of this study were to identify the optimal cut-off value and determine the prevalence, predictors and adverse outcomes of HBW in a suburban area of Cameroon.

Design: A 6-year retrospective register analysis and a 3-month prospective phase.

Setting: A secondary care level (regional) hospital in the city of Buea (southwest region of Cameroon).

Participants: Women who delivered in this hospital over a 6-year period (retrospective phase) and consenting pregnant mothers and their infants (singletons, born at $>28$ weeks gestation) (prospective phase).

Outcome measures: 90th centile of birth weights; prevalence of HBW defined as birth weight above the 90th centile; sociodemographic, maternal and obstetrical factors associated with HBW; maternal and neonatal adverse outcomes of HBW.

Results: Of the 4941 newborns reviewed in registers, the 90th centile of birth weights was $3850 \mathrm{~g}$. Using this new cut-off, we obtained a prevalence of $14.0 \%$ for HBW in the 200 newborns included in the prospective phase. This was significantly higher than the prevalence $(9.5 \%)$ yielded when the traditional cut-off of $4000 \mathrm{~g}$ was used $(p=0.003)$. None of the factors assessed was independently associated with HBW. Newborns with HBW were more likely to have shoulder dystocia $(p<0.01)$, and their mothers more likely to suffer from prolonged labour $(p=0.01)$ and postpartum haemorrhage $(p<0.01)$.

Conclusions: The results of this study suggest that the cut-off for HBW in this population should be $3850 \mathrm{~g}$. Thus, 3 of every 10 babies born with HBW in this hospital are likely not receiving optimal postnatal care because $4000 \mathrm{~g}$ is currently used to qualify for additional support.

\section{INTRODUCTION}

High birth weight (HBW) is defined as any birth weight found above the 90th centile of

\section{Strengths and limitations of this study}

- The study uses nearly 5000 newborns to provide a statistically accurate cut-off value for high birth weight (HBW) that may be useful in clinical practice.

- The study showed the extent to which using the traditional 'developed-world' cut-off value for HBW may underestimate the prevalence of HBW in developing countries.

- The study had a retrospective component, which was subject to a potential risk of incorrectly completed records.

- As a hospital-based study, neonates born at home could not be included.

weight for that gestation. ${ }^{1}$ The prevalence and trend of HBW vary across countries. Studies have shown an apparent decreasing trend in the prevalence of HBW from $10.2 \%$ in 1996 to $9.2 \%$ in 2002 , in the USA, ${ }^{2}$ whereas in Denmark, the prevalence is reported to have increased from $16.7 \%$ in 1990 to $20.0 \%$, in $1999 .{ }^{3}$ It is generally accepted that HBW occurs in about $3-15 \%$ of all pregnancies; recent studies in sub-Saharan Africa (SSA) have reported a prevalence of $14.7 \% .^{5}$

$\mathrm{HBW}$ is an emerging problem in developing countries. This is due to the growing burden of obesity and diabetes in these societies, attributed to urbanisation and changes in lifestyle patterns. ${ }^{5}{ }^{6}$ Despite the fact that such factors increase the risk of having babies with HBW, there are few reports on the topic in SSA. HBW is associated with perinatal morbidity and mortality. Studies have shown a significant association between HBW and traumatic births, perineal tears, prolonged labour, postpartum haemorrhage, increased rates of operative deliveries, neonatal hypoglycaemia, shoulder dystocia, birth asphyxia and death. ${ }^{7-9}$ 
Furthermore, whether the traditional cut-off value of $4000 \mathrm{~g}$ is suitable for clinical use everywhere remains unanswered. The WHO recommends that such cut-off values be used only for epidemiological purposes, and that each population should identify its specific cut-off for clinical use. ${ }^{10}$ In this study, we sought to establish a cut-off value for HBW in a suburban hospital, using the definition of HBW as all weights that fall above the 90th centile for the local newborn population. We also prospectively assessed the prevalence, predictors and adverse outcomes of HBW, using the new cut-off.

\section{METHODS}

Study design and setting

We carried out a two-phase descriptive study at the Buea Regional Hospital (BRH): a retrospective register audit to identify the cut-off value for HBW, followed by a prospective study to determine the prevalence, predictors and adverse outcomes of HBW.

The BRH is situated in the Buea Health District (BHD) in the Fako Division. The BRH is the referral hospital in the health district and it performs more deliveries than all the other health facilities in the district combined. The hospital uses all standard units of general medicine. An obstetrician and a paediatrician run the maternity and paediatric units, respectively, but there is no neonatal intensive care unit.

\section{Participants and sampling}

The recruitment of participants was described in a previous study by the same authors. ${ }^{11}$ For the retrospective phase, the records of all pregnant women who gave birth from January 2007 to December 2012 (6 years) were reviewed, and data of mother-infant pairs were included if they fulfilled the inclusion criteria. Information was said to be complete if it contained maternal age, marital status, gestational age, type of delivery, birth weight, newborn gender and Apgar score at the first minute.

For the prospective phase, the target study population included all pregnant mother-infant pairs who gave birth at the BRH from 2 January to 23 March 2013 (3 months); we excluded women who delivered at a gestational age below 28 weeks, those who had a multiple pregnancy and those who did not consent to take part in the study.

\section{Data collection, variables and measurements}

In the retrospective phase, we collected sociodemographic and clinical data from registers that had been filled in by the obstetrician, midwives and nurses who worked in the maternity unit.

In the prospective phase, pregnant women who were about to give birth were monitored making sure that they were provided with standard care, and the following data were extracted from their hospital records and completed by a history taken after delivery:

- Sociodemographic characteristics: average income per day and level of education.
- Obstetric history (gravid status, previous formula feeding and previous birth weights).

- Medical history (personal and family history of diabetes and prepregnancy weight).

We measured participants' weight to the nearest kilogram, using a Camry bathroom scale, and height to the nearest centimetre, using a locally made stadiometer, calibrated to the Butterfly tape. A standard physical examination was performed. Throughout the labour, the fetus was monitored for the presence of acute fetal distress (fetal heart rate $<120 \mathrm{bpm}$ or persistently above $160 \mathrm{bpm}$ and/or green meconium-stained amniotic fluid at delivery).

After delivery, the neonates were assessed for viability (breathing, heartbeat, pulsation of the umbilical cord or definite movements of voluntary muscles), and their Apgar scores at the 1st, 5th and 10th minutes were assessed. The presence of birth injuries was evaluated and the baby's weight was measured to the nearest gram, using a Holtex+ digital baby scale. The babies were monitored for the presence of respiratory distress (which was identified by any one of the following: respiratory grunting, nasal flaring, intercostal recessions, subxiphoid recession, thoracoabdominal asynchrony or respiratory rate $>60 \mathrm{bpm}$ ). Any neonatal death occurring during the period of monitoring was also noted.

Informed consent was then obtained after delivery. The newborns and their mothers were observed until the day of discharge, which could be up to 10 days for complicated deliveries that included caesarean sections or instrumental deliveries.

\section{Data management and statistical analysis}

Data were cross-checked for errors and stored securely in a private location; all data were kept confidential. Data were analysed using Epi Info V.3.5.4. Means (SD) were used to summarise continuous variables, and frequencies were used for categorical variables. Frequencies were compared using the Fisher's exact test. The McNemar test was used to assess the prevalence of HBW, comparing the traditional cut-off $(4000 \mathrm{~g})$ to that obtained by the newly identified cut-off, so as to account for dependency. Predictors of HBW were determined using bivariate and multiple logistic regression models. The models included all variables with $\mathrm{p}$ values $\leq 0.25$ in the bivariate analyses. ${ }^{12}$ For all these analyses, the significance was set at 0.05 .

\section{Ethical considerations}

The study received administrative clearance from the Regional Delegation of Public Health for the South West region and from the Director of the BRH. Confidentiality was ensured during the whole process. Participants were referred to only by identification numbers, and identifiable information (consent form) was kept separate from the data collection forms; it was only possible to link both through a coding sheet-available solely to the research team. 


\section{RESULTS}

\section{Demographic and obstetrical characteristics}

A total of 4941 newborn records were included in the retrospective phase and 200 pregnant women enrolled during the prospective phase. The mean age of the mothers was 26.4 (5.5) and 26.4 (5.8) years, respectively, for the retrospective and prospective phases of the study. The majority were married, half were unemployed, $99 \%$ had received at least a primary level of education and $93.4 \%$ of the women reported spending more than US $\$ 1$ a day (table 1). In regard to obstetrical characteristics in the prospective phase, $34.5 \%$ were primigravidae.

\section{Distribution of birth weight and prevalence of HBW}

The cut-off to define HBW (90th centile of birth weights) in the 4941 newborns during the retrospective phase was $3850 \mathrm{~g}$ (figure 1). Term deliveries accounted for $89.9 \%$ of the total deliveries and the 90th centile among this subgroup was also $3850 \mathrm{~g}$. In the prospective study, 28 babies had birth weights $\geq 3850 \mathrm{~g}$, giving a prevalence of $14.0 \%$ (95\% CI $9.5 \%$ to $19.6 \%$ ). Using the cut-off of $4000 \mathrm{~g}$, the prevalence was $9.5 \%$ (95\% CI 5.8\% to $14.4 \%)$. There was a significant difference in prevalence using the two cut-off levels $(\mathrm{p}=0.003)$.

\section{Predictors of HBW}

In the bivariate analysis, spending $\geq$ US $\$ 1$ a day $(\mathrm{p}=0.05)$, a history of a previous HBW pregnancy $(\mathrm{p}<0.01)$ and maternal prepregnancy body mass index

\begin{tabular}{|c|c|c|}
\hline Groups & Number & Frequency (\%) \\
\hline \multicolumn{3}{|l|}{ Marital status $(\mathrm{N}=200)$} \\
\hline Married & 114 & 57.0 \\
\hline Single & 85 & 42.5 \\
\hline Widow & 1 & 0.5 \\
\hline \multicolumn{3}{|l|}{ Occupation ( $\mathrm{N}=200)$} \\
\hline Unemployed & 101 & 50.5 \\
\hline Employed & 38 & 19.0 \\
\hline Self-employed & 61 & 30.5 \\
\hline \multicolumn{3}{|l|}{ Level of education $(\mathrm{N}=199)$} \\
\hline None & 2 & 1.0 \\
\hline Primary & 38 & 19.1 \\
\hline Secondary first cycle & 70 & 35.2 \\
\hline Secondary second cycle & 28 & 14.1 \\
\hline Tertiary & 61 & 30.7 \\
\hline \multicolumn{3}{|l|}{ Age groups $(\mathrm{N}=200)$ (years) } \\
\hline $15-19$ & 30 & 15.0 \\
\hline $20-36$ & 159 & 79.5 \\
\hline $37-44$ & 11 & 5.5 \\
\hline \multicolumn{3}{|l|}{ Gravidity (N=200) } \\
\hline$<5$ & 171 & 85.5 \\
\hline$\geq 5$ & 29 & 14.5 \\
\hline \multicolumn{3}{|l|}{ Parity $(\mathrm{N}=200)$} \\
\hline Nulliparous (parity=0) & 90 & 45.0 \\
\hline Multiparous (parity >1) & 110 & 55.0 \\
\hline
\end{tabular}

(BMI) $\geq 25 \mathrm{~kg} / \mathrm{m}^{2}(\mathrm{p}=0.03)$ were significantly associated with HBW (table 2).

In multivariate analysis, none of the variables tested were independently associated with HBW (table 3).

\section{Adverse outcomes of HBW}

Compared with mothers of babies with normal or low birth weight, mothers of neonates with HBW were about twice as likely to have prolonged labour $(p=0.01)$ and five-fold more likely to have postpartum haemorrhage $(p<0.01)$. Furthermore, HBW neonates were 15-fold more likely to have shoulder dystocia during delivery $(\mathrm{p}<0.01)$ (table 4).

When comparing the neonates who fell within the birth weight category of $3850-4000 \mathrm{~g}$ to those in the category $<3850 \mathrm{~g}$, the only excess complication found was in maternal postpartum haemorrhage $(2 / 9$ vs $5 / 172$; $\mathrm{p}=0.04)$.

\section{DISCUSSION}

In this study, we found that the 90th centile of birth weights that defines HBW in babies born in the BRH was $3850 \mathrm{~g}$. Using this as the cut-off value for HBW yielded a prevalence of $14.0 \%$, which was significantly higher than the prevalence obtained when using the traditional cut-off value of $4000 \mathrm{~g}(9.5 \%)$. Newborns with HBW ( $\geq 3850 \mathrm{~g}$ ) were more likely to suffer from shoulder dystocia, while their mothers were more likely to have prolonged labour and postpartum haemorrhage.

Few studies have attempted to generate locality-specific cut-off values for the definition of HBW. Most studies either established several values for large for gestational age, for specific gestational ages, ${ }^{13-15}$ or used the arbitrary cut-off values of 4000 or $4500 \mathrm{~g} .{ }^{8}{ }^{16}$ Developed countries across Europe, and the USA and Australia, with high mean birth weights ranging from 3400 to $3600 \mathrm{~g},{ }^{16-18}$ usually adopt the higher arbitrary cut-off value of $4500 \mathrm{~g}$. Meanwhile, less-developed countries such as Nigeria, Cameroon and Tanzania, with lower mean birth weights, ranging from 3000 to $3100 \mathrm{~g},{ }^{19-21}$ adopt the lower arbitrary value of $4000 \mathrm{~g}$ for $\mathrm{HBW}^{22}$ However, such disparities in trends for birth weight emphasise the need for locality-specific cut-off values for HBW. Our study, therefore, provides a statistically valid cut-off value for HBW for suburban use in Cameroon. This is in compliance with recent WHO recommendations for the adoption of region-specific cut-off values for birth weight distribution.

In SSA, Lawoyin, ${ }^{23}$ in Nigeria, used a cut-off value for HBW at $3800 \mathrm{~g}$ among term babies, in 1993. Our study has established a value of $3850 \mathrm{~g}$ for term babies, which is similar. However, these different cut-off values further suggest disparities in birth weight trends and emphasise the need for country/locality-specific HBW cut-off values for clinical management.

The prevalence of HBW, using the traditional cut-off value in our study $(9.5 \%)$, was higher than that obtained 
Figure 1 Distribution of birth weights and cut-off for high birth weight $(n=4941)$. The bell-shaped blue curve shows that the birth weights in the Buea Regional Hospital have a Gaussian distribution. The red line corresponds to the 90th centile of birth weights in our population (3850 g), while the blue lines show the frequencies for the various birth weights.

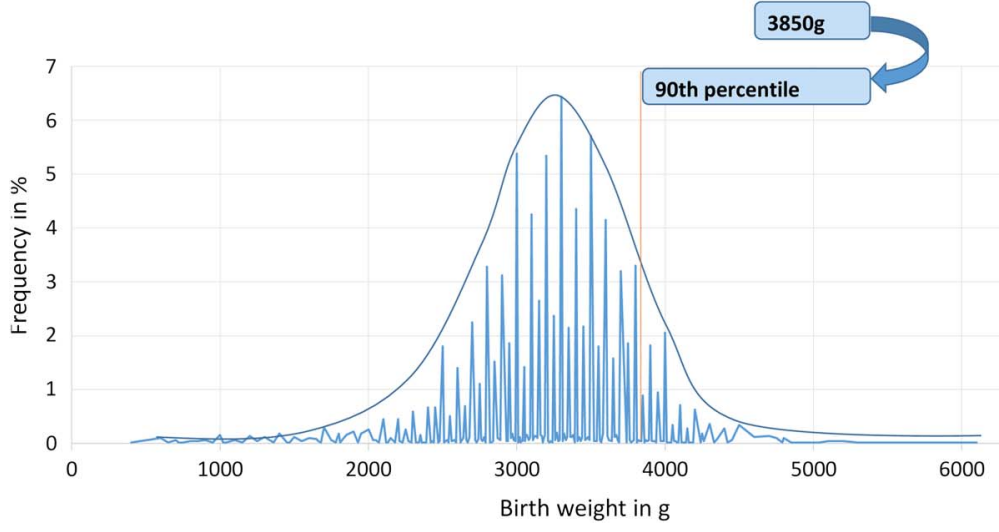

7000

by Abena Obama et $a l^{9}(6.0 \%)$ and Tebeu et $a l^{24}(4.3 \%)$ in 1995 and 2005, respectively, in Cameroon, suggesting that $\mathrm{HBW}$ is becoming more prevalent over time.

When $3850 \mathrm{~g}$ was used to define HBW, a higher prevalence $(14.0 \%)$ was obtained. This suggests that about 3 of every 10 newborns with $\mathrm{HBW}$ and their mothers may be excluded from receiving appropriate care while in hospital. The prevalence of HBW is underestimated using the traditional cut-off. These findings need confirming in further studies.

Although overweight or obesity before pregnancy, previous $\mathrm{HBW}$ and spending $\geq$ US $\$ 1$ a day were associated with HBW in bivariate analysis, none of these were independent predictors of HBW in multivariate analysis. This may be due to the small number of HBW babies, which potentially decreased the power of multivariate analysis.

Table 2 Bivariate analysis of potential associations with HBW (>3850 g) deliveries

\begin{tabular}{|c|c|c|c|c|c|c|}
\hline Variable & $\begin{array}{l}\text { Total } \\
\mathbf{N}\end{array}$ & $\begin{array}{l}\text { HBW } \\
\mathbf{N}\end{array}$ & HBW (\%) & OR & $95 \% \mathrm{Cl}$ & p Value \\
\hline \multicolumn{7}{|c|}{ Maternal age $(\mathrm{N}=200)$ (years) } \\
\hline$\leq 36$ & 189 & 26 & 13.8 & 1.0 & & \\
\hline$>36$ & 11 & 2 & 18.2 & 0.7 & 0.2 to 3.5 & 0.50 \\
\hline \multicolumn{7}{|c|}{ Average amount spent per day } \\
\hline$<$ US\$1 & 39 & 2 & 5.1 & 1.0 & & \\
\hline$\geq$ US\$1 & 143 & 24 & 16.8 & 3.7 & 0.8 to 16.5 & 0.05 \\
\hline \multicolumn{7}{|l|}{ Gravidity } \\
\hline$<5$ & 171 & 24 & 14.0 & 1.0 & & \\
\hline$\geq 5$ & 29 & 4 & 13.8 & 1.0 & 0.3 to 3.2 & 0.61 \\
\hline \multicolumn{7}{|c|}{ Gestational age (weeks) } \\
\hline$\leq 40$ & 168 & 24 & 14.3 & 1.0 & & \\
\hline$>40$ & 32 & 4 & 12.5 & 1.2 & 0.4 to 3.6 & 0.52 \\
\hline \multicolumn{7}{|c|}{ Previous HBW } \\
\hline No & 178 & 20 & 11.2 & 1.0 & & \\
\hline Yes & 22 & 8 & 36.4 & 4.5 & 1.7 to 12.1 & $<0.01$ \\
\hline \multicolumn{7}{|c|}{ History of diabetes } \\
\hline Yes & 2 & 0 & 0.0 & - & & \\
\hline No & 198 & 28 & 14.1 & - & - & 0.74 \\
\hline \multicolumn{7}{|c|}{ Family history of diabetes } \\
\hline No & 173 & 23 & 13.3 & 1.0 & & \\
\hline Yes & 27 & 5 & 18.5 & 1.5 & 0.5 to 4.3 & 0.32 \\
\hline \multicolumn{7}{|c|}{ Maternal height (cm) } \\
\hline$\leq 160$ & 96 & 12 & 12.5 & 1.0 & & \\
\hline$>160$ & 103 & 16 & 15.5 & 1.3 & 0.6 to 2.9 & 0.34 \\
\hline \multicolumn{7}{|c|}{ Weight gain in pregnancy (kg) } \\
\hline$\leq 15$ & 89 & 11 & 12.4 & 1.0 & & \\
\hline$>15$ & 43 & 10 & 23.3 & 2.2 & 0.8 to 5.5 & 0.09 \\
\hline \multicolumn{7}{|c|}{ Prepregnancy BMI $\left(\mathrm{kg} / \mathrm{m}^{2}\right)$} \\
\hline$<25$ & 77 & 8 & 10.4 & 1.0 & & \\
\hline$\geq 25$ & 54 & 13 & 24.1 & 2.7 & 1.0 to 7.2 & 0.03 \\
\hline
\end{tabular}


Table 3 Multivariate analysis of potential predictors of high birth weight $(\mathrm{HBW} ;>3850 \mathrm{~g})$ deliveries

\begin{tabular}{llll}
\hline & $\begin{array}{l}\text { Adjusted } \\
\text { Variable }\end{array}$ & $\mathbf{9 5 \%} \mathbf{C l}$ & p Value \\
\hline $\begin{array}{l}\text { Weight gain }>15 \mathrm{~kg} \\
\text { (yes/no) }\end{array}$ & 2.8 & 0.9 to 8.2 & 0.07 \\
$\begin{array}{l}\text { Prepregnancy } \\
\text { obesity (yes/no) }\end{array}$ & 2.5 & 0.8 to 7.9 & 0.12 \\
$\begin{array}{l}\text { Income }>\text { US } \$ 1 \mathrm{a} \\
\text { day (yes/no) }\end{array}$ & 2.1 & 0.4 to 10.4 & 0.40 \\
$\begin{array}{l}\text { Previous HBW } \\
\text { (yes/no) }\end{array}$ & 3.5 & 0.9 to 13.0 & 0.07 \\
\hline HBW, high birth weight; USD, United StatesUSA dollars. &
\end{tabular}

Several reports have stressed the phenomenon of repeat outcomes from one pregnancy to the next. ${ }^{25}$ In our study, pregnant women with a previous HBW newborn were more likely to have another in the current pregnancy. However, a previous study carried out by Defo and Partin ${ }^{26}$ showed that previous birth weight had a significant effect on later birth weight in the USA but not in Cameroon.

Women in our study who were overweight or obese before pregnancy were more likely to have a HBW neonate. Lawoyin, ${ }^{23}$ in Nigeria, showed that maternal BMI was positively associated with the delivery of large babies. Few studies have tried to assess the impact of maternal income level on birth weight. Women who regularly spent more money were more likely to have a HBW neonate. This could be because these women were more overweight or obese, or had access, more than others, to protein and calorie-rich diets adding to the growth of their fetuses.

Neonates with HBW were more likely to suffer from shoulder dystocia during delivery. Abena Obama et al, ${ }^{9}$ in Cameroon, also found that shoulder dystocia was a leading complication of macrosomia, and Anya and Anya $^{7}$ found the same. Additionally, in our study, mothers who had HBW neonates were more likely to have prolonged labour and postpartum haemorrhage. Mocanu et $a l^{8}$ pointed out in their study that women who had macrosomic babies were more likely to have prolonged labour especially if they were primiparae. Anya and Anya ${ }^{7}$ also indicated that postpartum haemorrhage was a common complication among women who had HBW infants.

Mothers of neonates who fell within the birth weight category of $3850-4000 \mathrm{~g}$ in our study were more likely to have complications (postpartum haemorrhage) than those in the category of $<3850 \mathrm{~g}$. It might therefore be prudent for clinicians to be more watchful when dealing with birth weights $>3850 \mathrm{~g}$.

Our study had the following potential limitations: it was carried out in a single health facility, therefore a substantial number of babies born at home were not included. Thus, the results may not reflect the situation in the whole district. Also, the retrospective phase is subject to a potential risk of inaccurate data recording. Some risk factors (mother's income and history of diabetes) were subjective, since they were based on mother's recall. Some relevant neonatal complications, such as hypoglycaemia, were not assessed because we were not granted ethical approval for testing. The relatively small sample size of the prospective phase may not be sufficient for multivariate analysis to identify the independent predictors of HBW. However, to the best of our knowledge, this is the first study to have generated a statistical and clinically relevant cut-off value for HBW for local application, using a sample of almost 5000 babies.

\section{CONCLUSIONS}

On the basis of suggested new cut-off value, one of every seven babies born in the hospital has HBW. Mothers of neonates who fall within the newly defined category of HBW (3850-4000 g) are more likely to have complications than those who fall below this cut-off. It is therefore reasonable to suggest that the definition of HBW in suburban areas in Cameroon be lowered to allow all babies $\geq 3850 \mathrm{~g}$ to benefit from appropriate surveillance and care. In addition, because of the well-established association of HBW with diabetes, mothers of these neonates may benefit from diabetes screening after delivery, and should have their neonates tested for

Table 4 Neonatal and maternal complications of HBW (>3850 g) deliveries

\begin{tabular}{|c|c|c|c|c|c|c|}
\hline Complications & $\begin{array}{l}\text { HBW } \\
\mathbf{N}\end{array}$ & $(\%)$ & $\begin{array}{l}\text { NLBW } \\
\mathbf{N}\end{array}$ & $(\%)$ & Total & p Value \\
\hline Neonatal asphyxia (1st minute) & 10 & 35.7 & 62 & 36.0 & 72 & 0.6 \\
\hline Neonatal asphyxia (5th minute) & 4 & 14.3 & 29 & 16.9 & 33 & 0.5 \\
\hline Neonatal asphyxia (10th minute) & 1 & 3.6 & 17 & 9.9 & 18 & 0.3 \\
\hline Fetal distress & 6 & 21.4 & 33 & 19.2 & 39 & 0.4 \\
\hline Respiratory distress & 1 & 3.6 & 13 & 7.6 & 14 & 0.4 \\
\hline Neonatal death & 2 & 7.1 & 14 & 8.1 & 16 & 0.6 \\
\hline Shoulder dystocia & 5 & 17.9 & 2 & 1.2 & 7 & $<0.01$ \\
\hline Prolonged labour (>12 hours) & 12 & 42.9 & 35 & 20.3 & 47 & 0.01 \\
\hline Postpartum haemorrhage & 5 & 17.9 & 5 & 2.9 & 10 & $<0.01$ \\
\hline
\end{tabular}


hypoglycaemia. We require further studies to confirm these preliminary findings.

\section{Author affiliations}

${ }^{1}$ Department of Internal Medicine and Paediatrics, Faculty of Health Sciences, University of Buea, Buea, Cameroon

${ }^{2}$ Health and Human Development (2HD) Research Group, Douala, Cameroon

${ }^{3}$ Diabetes and Endocrine Unit, Department of Internal Medicine, Douala

General Hospital, Douala, Cameroon

${ }^{4}$ Department of Public Health and Hygiene, Faculty of Health Sciences,

University of Buea, Buea, Cameroon

${ }^{5}$ NIHR Biomedical Research Unit in Nutrition, Diet and Lifestyle, University of Bristol, Bristol, UK

${ }^{6}$ Department of Obstetrics and Gynaecology, Faculty of Medicine and

Biomedical Sciences, University of Yaounde 1, Yaounde, Cameroon

Acknowledgements The authors express their gratitude to the Buea Regional Hospital for allowing them to use the hospital premises, and to the pregnant women who took part in this study.

Contributors S-PC, TN, JA and RM contributed to the study concept and design. SPC, TN and JA contributed to the acquisition of data. SPC, TN, JA and JPH-S contributed to data interpretation and analysis. S-PC, TN, JA, $\mathrm{JPH}-\mathrm{S}$ and RM contributed to manuscript writing and revisions.

Funding The 2HD Research Group is supported by a Cruddas Link Fellowship to S-PC (Tseu Medical Institute, Harris Manchester College, University of Oxford, UK), and receives technical assistance from the NIHR-Bristol Biomedical Research Unit (BRU) in Nutrition, University of Bristol, UK.

Competing interests None declared.

Ethics approval Ethical approval was obtained from the Institutional Review Board of the Faculty of Health Sciences, University of Buea.

Provenance and peer review Not commissioned; externally peer reviewed.

Data sharing statement No additional data are available.

Open Access This is an Open Access article distributed in accordance with the Creative Commons Attribution Non Commercial (CC BY-NC 4.0) license, which permits others to distribute, remix, adapt, build upon this work noncommercially, and license their derivative works on different terms, provided the original work is properly cited and the use is non-commercial. See: http:// creativecommons.org/licenses/by-nc/4.0/

\section{REFERENCES}

1. Rahimian J, Varner MW. Disproportionate fetal growth. In: Decherney AH, Nathan L, Goodwin TM, Laufer N, eds. Current diagnosis \& treatment in obstetrics \& gynecology. 10 edn. New York: Sydney: McGraw-Hill Medical, 2007.

2. Chauhan SP, Grobman WA, Gherman RA, et al. Suspicion and treatment of the macrosomic fetus: a review. Am J Obstet Gynecol 2005;193:332-46.

3. Orskou J, Kesmodel U, Henriksen TB, et al. An increasing proportion of infants weigh more than 4000 grams at birth. Acta Obstet Gynecol Scand 2001;80:931-6.
4. Asplund CA, Seehusen DA, Callahan TL, et al. Percentage change in antenatal body mass index as a predictor of neonatal macrosomia. Ann Fam Med 2008;6:550-4.

5. Ojule JD, Fiebai PO, Okongwu C. Perinatal outcome of macrosomic births in Port Harcourt. Niger J Med 2010;19:436-40.

6. Kamadjeu RM, Edwards R, Atanga JS, et al. Anthropometry measures and prevalence of obesity in the urban adult population of Cameroon: an update from the Cameroon Burden of Diabetes Baseline Survey. BMC Public Health 2006;6:228.

7. Anya SE, Anya AE. Macrosomia: a case-control study of risk factors and outcome. Highland Med Res J 2006;4:97-106.

8. Mocanu EV, Greene RA, Byrne BM, et al. Obstetric and neonatal outcome of babies weighing more than $4.5 \mathrm{~kg}$ : an analysis by parity. Eur J Obstet Gynecol Reprod Biol 2000;92:229-33.

9. Abena Obama MT, Shasha VW, Fodjo J, et al. Foetal macrosomia in Cameroon: prevalence, risk factors and complications. West Afr J Med 1995;14:249-54.

10. UNICEF, WHO. Low birthweight: country, regional and global estimates. New York: UNICEF Editorial and Publications section, 2004:1-27.

11. Njim T, Atashili J, Mbu R, et al. Low birth weight in a sub-urban area of Cameroon: an analysis of the clinical cut-off, incidence, predictors and complications. BMC Pregnancy Childbirth 2015;15:288.

12. Bursac Z, Gauss $\mathrm{CH}$, Williams DK, et al. Purposeful selection of variables in logistic regression. Source Code Biol Med 2008;3:17.

13. Arbuckle TE, Wilkins R, Sherman GJ. Birth weight percentiles by gestational age in Canada. Obstet Gynecol 1993;81:39-48.

14. Guaran RL, Wein $\mathrm{P}$, Sheedy $\mathrm{M}$, et al. Update of growth percentiles for infants born in an Australian population. Aust $N Z \mathrm{~J}$ Obstet Gynaecol 1994;34:39-50.

15. Beeby PJ, Bhutap T, Taylor LK. New South Wales populationbased birthweight percentile charts. J Paediatr Child Health 1996;32:512-18.

16. Rode L, Hegaard HK, Kjaergaard $\mathrm{H}$, et al. Association between maternal weight gain and birth weight. Obstet Gynecol 2007:109:1309-15.

17. Dobbins TA, Sullivan EA, Roberts $\mathrm{CL}$, et al. Australian national birthweight percentiles by sex and gestational age, 1998-2007. Med J Aust 2012;197:291-4.

18. Donahue SM, Kleinman KP, Gillman MW, et al. Trends in birth weight and gestational length among singleton term births in the United States: 1990-2005. Obstet Gynecol 2010;115:357-64.

19. Lawoyin TO, Oyediran AB. A prospective study on some factors which influence the delivery of low birth weight babies in a developing country. Afr J Med Med Sci 1992;21:33-9.

20. Lewis JR. Birth weights of infants in the Cameroon grasslands. Bull World Health Organ 1974:50:575-6.

21. Ubomba-Jaswa P, Ubomba-Jaswa SR. Correlates of low birth weigh in Tanzania. SA J Dem 1996:6:64-73.

22. Onyiriuka AN. High birth weight babies: incidence and foetal outcome in a mission hospital in Benin City, Nigeria. Niger $J$ Clin Pract 2006;9:114-19.

23. Lawoyin TO. A prospective study on some factors which influence the delivery of large babies. J Trop Med Hyg 1993;96:352-6.

24. Tebeu PM, Mboudou E, Halle G, et al. Risk factors of delivery by caesarean section in Cameroon (2003-2004): a regional hospital report. ISRN Obstet Gynecol 2011;2011:791319.

25. Goldenberg RL, Hoffman HJ, Cliver SP, et al. The influence of previous low birth weight on birth weight, gestational age, and anthropometric measurements in the current pregnancy. Obstet Gynecol 1992;79:276-80.

26. Defo BK, Partin M. Determinants of low birthweight: a comparative study. J Biosoc Sci 1993;25:87-100. 